\title{
Spatio-Temporal Changing Scenario of Growth and Structure of Manufacturing Industries in Asansol- Durgapur Region, West Bengal
}

\author{
Gosai Maji $^{1^{*}}$ and Uma Shankar Malik ${ }^{1}$ \\ ${ }^{1}$ Department of Geography, Visva-Bharati, Santiniketan-731235, West Bengal, India.
}

\begin{abstract}
Authors' contributions
This work was carried out in collaboration with both authors. Author GM collected the data, managed the literature searches, designed the study, wrote the first draft of the manuscript, and performed the statistical analysis and interpretation. Author USM assisted and supervised the study with valuable suggestions and critical revision of each and every aspects of the research article. Both read and approved the final manuscript.

Article Information

DOI: $10.9734 / A J G R / 2021 / v 4 i 389$ Editor(s):

(1) Prof. Armando García Chiang, Universidad Autónoma Metropolitana, México. Reviewers:

(1) Ojwang' George Omondi, University of Nairobi, Kenya. (2) John Otieno, University of Science and Technology, Kenya. Complete Peer review History: http://www.sdiarticle4.com/review-history/69471
\end{abstract}

Original Research Article

Received 15 April 2021

Accepted 20 June 2021

Published 25 June 2021

\begin{abstract}
Asansol-Durgapur Industrial Region serves as nerve-knot of the economy of West Bengal as well as the entire economic region of Eastern India because of its enormous reservoir of excellent quality of coal of Raniganj Coalfield, outstanding network of transport by rail and road, skillful and cheap labour in close proximity of states. With the establishment of a number of large industrial units like Iron \& Steel Plant, Durgapur Steel Plant, Chittaranjan Locomotive works, Durgapur Alloy Steel Plant, Durgapur Thermal Power Station, and hundreds of medium and small-scale industries have made the region great industrial belt after Hooghly industrial belt in West Bengal. Though there was rapid industrialization after independence period but the growth of industries has not taken place uniformly throughout the study area. This is because, high manufacturing intensity found in Durgapur, Asansol, Raniganj and Kulti areas whereas the Salanpur, Jamuria, Fraidpur, Barabani areas witnesses low manufacturing intensity. The decadal growth of industries also noteworthy, in 1951 there were 46 industrial units and it increased to 430 in 2019. The number of basic metal and engineering units was 2 and 18 respectively in the year 1951 whereas in 2019 the basic metal and
\end{abstract}


engineering unit increased to 122 and 66 respectively. This paper primarily focuses on the estimation of spatial and temporal distribution of manufacturing industrial units, growth and structural changes, manufacturing intensity and concentration of the manufacturing sector during the period of 1951 to 2019 in Asansol-Durgapur Industrial Region.

Keywords: Manufacturing intensity; industrialization; concentration index; growth; structure.

\section{INTRODUCTION}

After the Second World War, the most the countries particularly the underdeveloped one had continued with the thought that the industrialization was a short cut to greater wealth [1]. Even the policy makers of most developing countries are of the view that Industrialisation is the only way out and pathway to eradicate their troubles of poverty, over population and economic backwardness and uplift the standard of living and quality of life. This paper makes an effort in terms of change, growth, development and the structure of the industry in respect to the growth of number of employment and industrial unit to evaluate the region's industrialization status. The significance of industrialisation considered as a goal of achieving economic prosperity and development; it has for long been in the thoughts and beliefs of development strategy for India. This is because those industries were established in quick progression during the post-independence period [2]. Behind the disruption of industrial activities there are lots of factors and state of affairs that may bring to a close or reverse the course of industrial activities; such as closing of units or untimely deindustrialization, which in turn have an effect on allocation of employment leading to modify in configuration of industries. During the study periods 1951-2019 in the Asansol-Durgapur Region the picture of growth and structural change is quite clear.

Economists since ages have been trapped in the cobweb of economic growth and development. From the classical economist to the neo classical economist; were in favour of investment in technological know-how [3] and human resources [4]. Successful industrialization are continuous processes and effort which involve transformation from one 'phase' to another through the set up of new industries with higher value added and advanced technological equipment [5]. However the process of economic development is not automatic as it emphasising on manpower with more skill, ability and talent, highly productive and modern advanced technological functions [6]. Since every country hankers after the development which is completely dependent on process of structural transformation from low productive sectors to high productive sectors [7]. Therefore, the structural change has become the central theme and aphorism of the scenario of modern economic growth and development [8]. The industrial sector is generally supposed to be a key engine of growth in the developmental process of economy and industrialisation, especially the growth in manufacturing sector [9].

Industrialization is considered to be the most significant engine of economic growth [10], Lavopa [11]. Besides, according to a number of economists and investigators; transformations from agricultural activity to manufacturing activity and from manufacturing activity to services sector is considered to be the clear indication of gradual progression of economic development $[12,13]$. Therefore, it is universally accepted point that without becoming an industrial command and supremacy no nation could develop [14]. In the latest paper Amirapu and Subramanian [15] it has been highlighted that manufacturing sector is considered as a prime driving factor of structural transformation and bring into being sustainable economic growth and development. Moreover, according to Barro [16], if a nation has healthier industrial set up and superior human resources and adequate capital level, entrepreneurs can launch developed and sophisticated technologies for domestic firms. There is close association between industrial development and economic growth. The manufacturing sector is referred to "the main engine of fast growth" [17]. Premature deindustrialization or non-industrialization has recently been conspicuous in developing countries with a poorer share of manufacturing in GDP at their zenith. Dasgupta and Singh [18]; Amirapu and Subramanian [15]; Rodrik [19]; Ghani and O'Connel [20]; Kathuria and Raj [21] surveyed 15 states of India and tested the hypothesis for the period of 1994-1995 to 20052006, and came to conclusion that manufacturing had without a doubt acted as an engine of growth and development in India, in spite of its waning share in GDP. As 
manufacturing plays a leading role in the real economy, Western developed countries tend to have developed "remanufacturing strategies" after the financial crisis of 2007-2008 in an effort to consolidate "state economic sovereignty". Manufacturing agglomeration serves as an important driving force accelerates the transformation and upgrading of structures [22]. The development of the manufacturing industry is becoming significant for the spatial reorganisation of manufacturing clusters [23]. Since the 1990s, the spatial agglomeration of manufacturing has become a hot topic in the industrial economy, spatial economy, and other economic areas. Most research focuses on the evolution and dynamic mechanism of spatial patterns of manufacturing enterprises [24]. More recently, scholars have started to pay attention to the spatial effect of the agglomeration economy [25], (Larson et all.,[26]. An enterprise gives great importance to technological innovation, talents, and industrial policy, etc. [27].

According to a series of current publications, Rodrik [28] assumed that the manufacturing sector, the engine of growth predominantly still holds for developing countries with a highest level of human resources and investment of capital. So the vital role of the activities of manufacturing sector as a driving factor of growth and development of economy can't be denied.

\section{OBJECTIVE OF THE STUDY}

The present paper revolves around the following objectives-

First: The fundamental objective of the study is to enquire into the different phases of growth and structure of manufacturing industries in terms of industrial unit and employment during post independence period.

Second: Assessing the discrepancy in manufacturing intensity and concentration of industries over space and time.

\section{METHODOLOGY}

Asansol-Durgapur Industrial Region surrounded by the river Ajoy, Barakar and Damodar appears to be looking glass reflection of the Rurh Industrial complex in the Rurh Coal mining district in relation to the Luppe, Rhine and Rurh River in the West Germany. The Region is considered to be second most important industrialised region of West Bengal next to the Hooghly Industrial Belt. The geographical location of the study region lies within the administrative control of 7 block, namely Salanpur, Baraboni, Jamuria, Andal, Raniganj, Faridpur- Durgapur, Kanksa and 3 municipality: Raniganj, Jamuria, Kulti and 2 municipal corporation: Asansol and Durgapur under Paschim Bardhaman district. The region is surrounded by the Ajoy River on the north, Damodar River on the south with latitudinal and longitudinal extension approximately of $23^{\circ} 25^{\prime}$ and $23^{\circ} 40^{\prime}$ and $86^{\circ} 40^{\prime}$ to $87^{\circ} 30^{\prime}$. The region spread over a region of about $1650 \mathrm{sq} \mathrm{km}$.

The region is economically developed region predominantly based on mining and industrial activity along with other trade \& commercial activities. Since post independence period the operation of industrial activity creates inertia to pull towards the region more industrial activity. Moreover, outstanding connectivity by the six lane national highway corridor, Eastern Railway route along this region and air network influences the economy of surrounding region (hinterland) and generates a connection with the other states and the urban industrial set up as well that plays pivotal role for the development of the entire region. Therefore, huge resource base and tremendous connectivity, and developed infrastructure produced a collective force for regional development in terms of transformation and revolution of regional economy which led to industrial growth and development. That's why the Asansol-Durgapur industrial region has been studied here from the view point of transformation of growth and development of industries.

The study is mainly based on secondary data collected from the Chief Inspector of Office, Paschim Bardhaman and website of annual survey of industries. For the purpose of the study, various journals and relevant published literatures have also been consulted to supplement the data. Firstly, the raw data was tabulated, analysed and interpreted with the help of statistical techniques in excel sheet, and then Mapping has been prepared by the QGIS. The study covered up the period of 1951 to 2019.

\section{RESULTS AND DISCUSSION}

The pattern of spatio-temporal growth and structure of manufacturing industries have shown a major change throughout the entire study period. The particulars can be grouped and 
discussed under the following heads.

\subsection{Growth and Structure of Industries}

During the period (1951-2019) the number of industrial units increased from 49 to 430 and number of factory employments from 39539 to 104187. However, the growth of industries has not taken place uniformly throughout the entire study period. Analysis of first decade showed an increase of 125percent. During the decade of 1961-71 and 1971-81 the growth was only 46percent and 30percent respectively; whereas negative growth rate found in industrial units being only 9percent during the decade of 19811991. The possible reason may be due industrial sickness all over the state during this period.
Subsequent to that, in the next two decades of 1991-2001 and 2001-2019 the number of industrial units increased to 85percent and 29.31 percent respectively. Number of employment increased to 41 percent in the very first decade and by 49percent in the next decade due primarily to the establishment of Durgapur industrial complex. In the decade (1971-81) growth in number of employment was very marginal; lower as compared to the earlier decade. During the decade 1981-1991 registered a negative growth of -13.5 percent due to large scale retirement and V.R.S. Thereafter it increased to 7.31percent (1991-2001) and all over again a negative growth rate of -5.11 percent experienced in the decade of 2001-2019 (See Table 1).

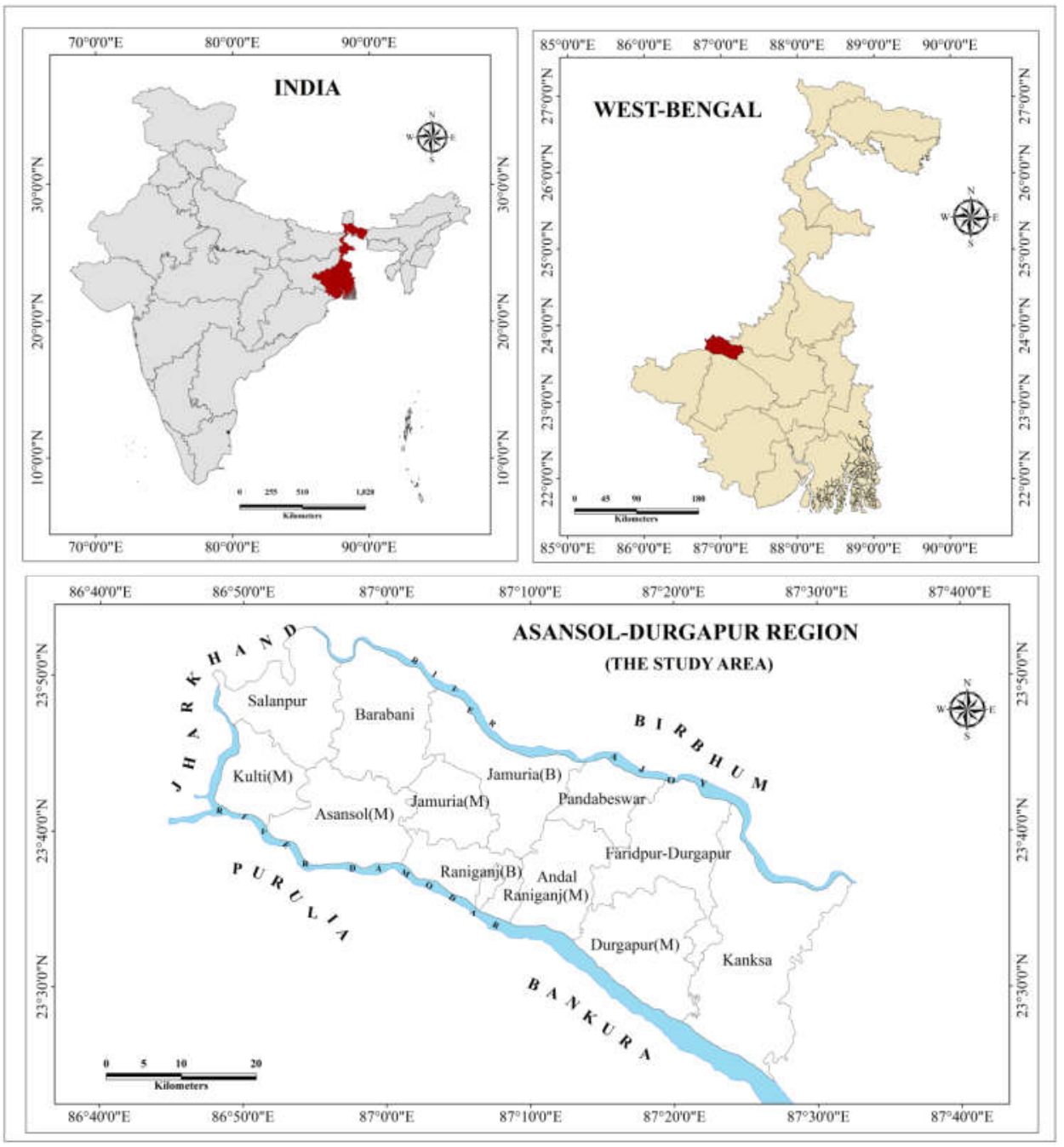

Fig. 1. Location map of the study region Sources: Prepared by the authors 


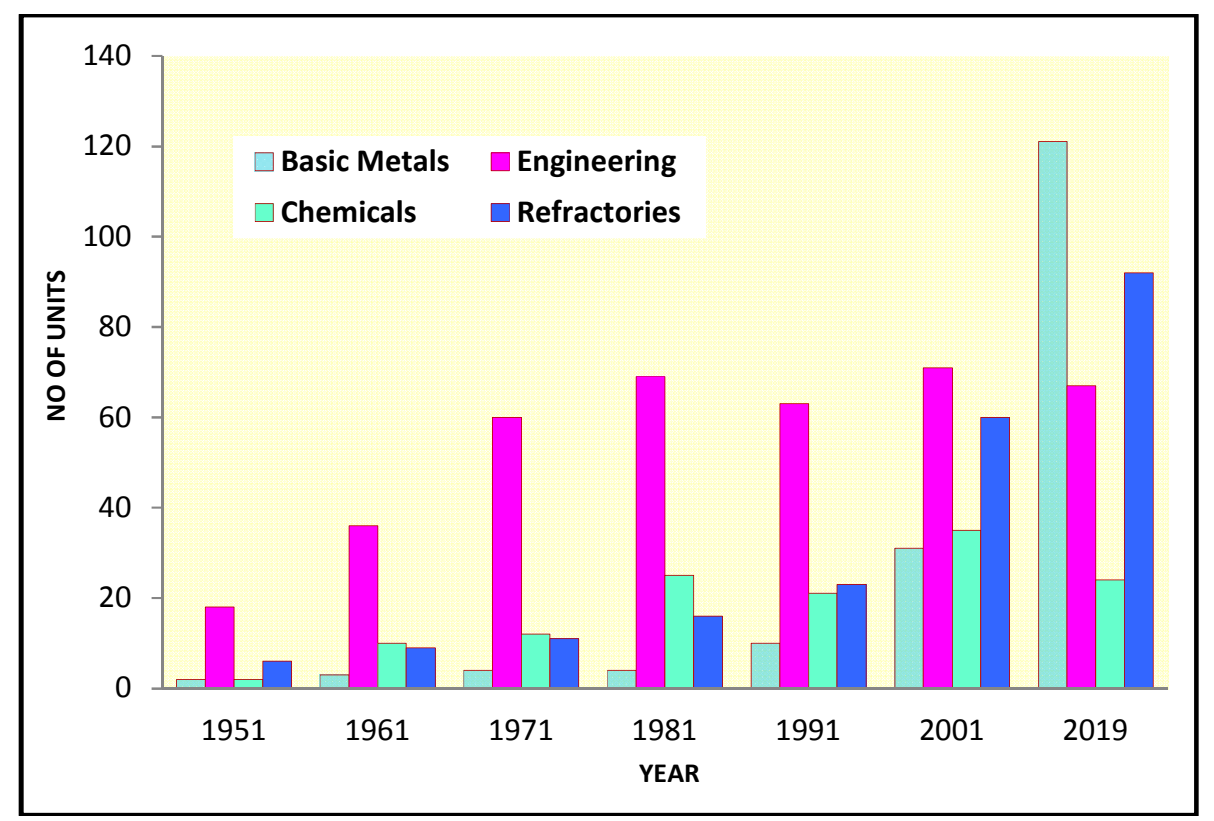

Fig. 2. Graphical representation of change in structure of selected industrial units Sources: Prepared by the authors on the basis of data given in Table-1

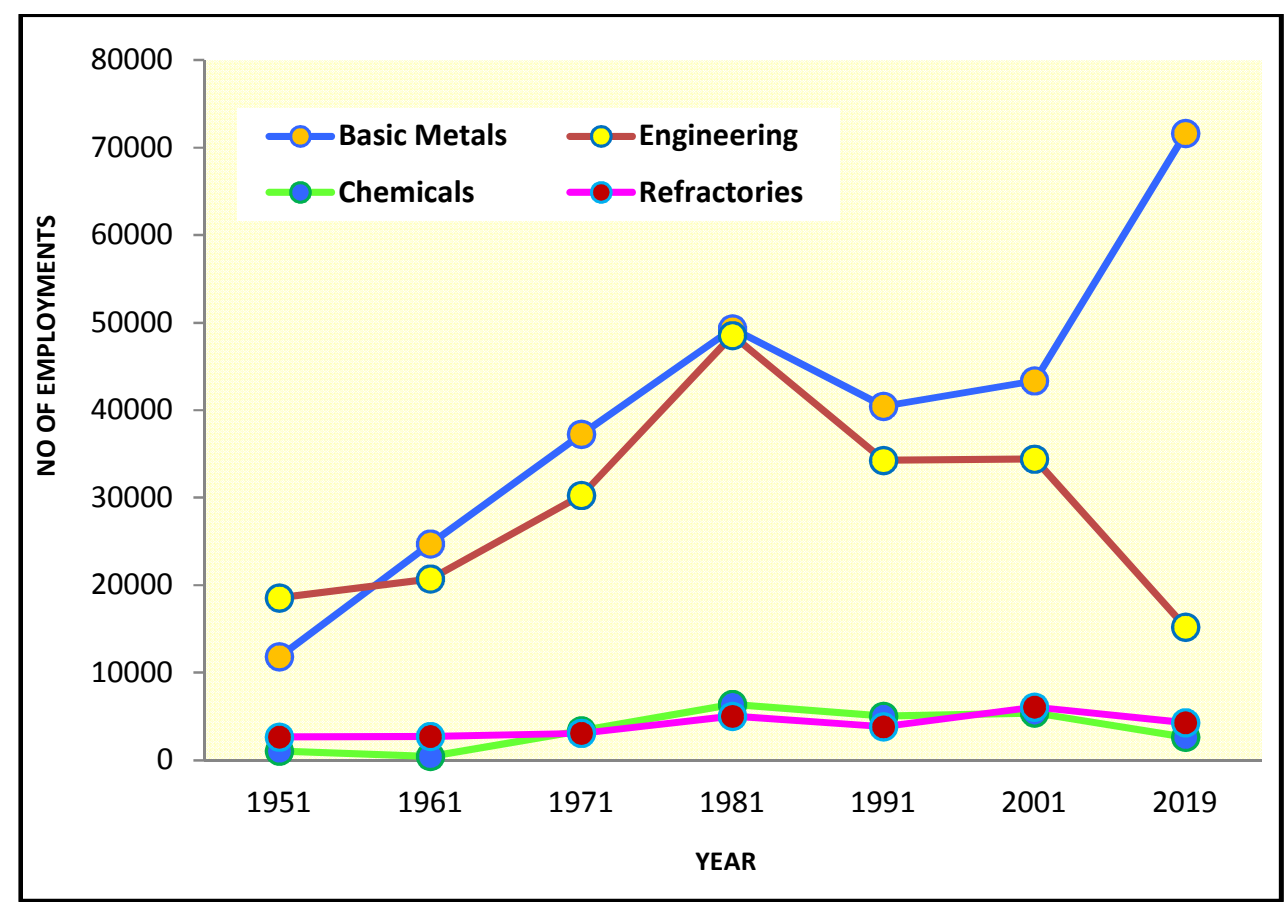

Fig. 3. Graphical representation of change in structure of selected industrial units Sources: Prepared by the authors on the basis of data given in Table 1

The major number of employment in the study region engaged in engineering industries was 49.3 percent of the total factory workers in 1951 but it progressively decreased and it was just only 14.61 percent in 2019 . In case of basic metal industries the percentage of employment was 31.5 percent in 1951 whereas it increased to 68.8 percent in 2019 (See Table 1). 
Table 1. Changes in structure in selected industries

\begin{tabular}{|c|c|c|c|c|c|c|c|c|c|c|}
\hline \multirow[t]{2}{*}{ Years } & \multicolumn{5}{|c|}{ Industrial Units } & \multicolumn{5}{|c|}{ Employment } \\
\hline & $\begin{array}{l}\text { Basic } \\
\text { Metals }\end{array}$ & Engineering & Chemicals & Refractory & Total Unit & Basic Metals & Engineering & Chemicals & Refractory & $\begin{array}{l}\text { Total } \\
\text { Employment }\end{array}$ \\
\hline 1951 & $2(4.3)$ & $18(39)$ & $2(4.3)$ & $6(13)$ & 46 & 11843(31.5) & $18557(49.3)$ & $1055(2.8)$ & $2661(7.1)$ & 37629 \\
\hline 1961 & $3(2.8)$ & $36(34.6)$ & $10(9.6)$ & $9(8.7)$ & 104 & $24729(44.9)$ & 20728(37.6) & $455(0.8)$ & 2731(5.0) & 55079 \\
\hline 1971 & $4(2.8)$ & $60(41.91)$ & $12(8.4)$ & $11(7.7)$ & 143 & $37263(45.4)$ & $30277(36.9)$ & $3388(4.1)$ & $3096(3.8)$ & 82038 \\
\hline 1981 & $4(2.0)$ & $69(34.8)$ & $25(12.6)$ & $16(8.1)$ & 198 & $49314(41.8)$ & $48531(41.1)$ & $6392(5.4)$ & $5030(4.3)$ & 118017 \\
\hline 1991 & $10(4.62)$ & $63(29.16)$ & $21(9.72)$ & $23(10.64)$ & 216 & $40461(39.6)$ & $34264(33.5)$ & $5042(4.9)$ & $3831(3.7)$ & 102074 \\
\hline 2001 & $31(9.33)$ & 71(21.38) & $35(10.54)$ & $60(18.07)$ & 332 & 43371(39.6) & $34424(31.4)$ & $5418(4.9)$ & $6085(5.5)$ & 109506 \\
\hline 2019 & $121(28.21)$ & $66(15.38)$ & $24(5.59)$ & 92(21.44) & 430 & 71636(68.81) & $15222(14.61)$ & $2632(2.53)$ & 4295(4.12) & 104187 \\
\hline
\end{tabular}
Sources: Office of the Chief Inspector of Factories \& computed by the authors. 
Another significant industry in the study region is the engineering industry. The units increased in number from 18 in 1951 to 66 in 2019. In the decade 1951-1961 experienced a 96percent increase in the number of units when there was an industrial explosion in the State subsequent independence and extensive economic rebuilding, renovation and rejuvenation. The subsequent decade $1961-71$ and the next one 1971- 1981 also registered growth in engineering units despite the fact that it was slower. But after 1981 the growth of engineering industrial unit declined whereas in the initial stage of the study period the number of industrial unit of basic metal was very low which was only 2, 3, 4 and 4 in the year 1951, 1961, 1971 and 1981 respectively but after 1981 the number of basic metal industrial unit was sharply increased to 121 in 2019, which is highest throughout the entire study period. The same trend has been found in case of refractory industrial unit whereas the number of chemical industrial unit has been sharply decreased (See Table 1).

During the decade 1981- 91 registered a negative growth of units since many of these closed down consequential in a decrease in the number of persons employed. In case of chemical industry, the number of units increased from 2 in 1951 to 24 in 2019. In the decade 1961-71, the set up of Durgapur Industrial complex encouraged the growth of numerous new units, a large number of them in and around Durgapur. It may be cited of the Durgapur Chemical established during this instance. In the decade of 1971-81 there was a 108percent increase in the number of units of chemical industry. During this decade there was satisfactory diversification with fresh units were set up at Salanpur, Asansol, Hindustan Cables and Barakar. However in the decade of 1981-91 recorded the closure of quite a lot of units, the majority of which had experienced definite operational difficulties. For this reason there was a declining trend in the number of units by 24 percent. Afterward in the subsequent decades 1991-2001 and 2001-2019 units increased by 66 percent and decreased -7.08 percent respectively. So the trend of chemical industrial unit has been fluctuated throughout the entire study period (See Table 1).

Refractory industry has registered consistently a positive trend of growth during the entire period. The successive growth rate was 50 percent increase in 1951-61, 45 per cent increase in 1971-81 and 53.33 percent growth in decades of 2001-2019 (See Figs. 2 and 3). The grounds behind positive growth in case of refractory industry are the increasing demand for refractory bricks. Moreover, the country's new industrial liberalisation policy has impacted upon rapidly increasing of steel plants all over the country. The Asansol-Durgapur being the significant provider of refractory materials and equipments for the entire country the industry continued emerging in the worst situation of industrial turmoil and instability during the last decade.

The four industrial units have been considered here give us an idea about attention-grabbing changes during the last six decades Consequently these differential growth rates in the midst of different industry groups, there has happened noteworthy structural changes in the manufacturing activities in the industrial units of the study region. In 1951, heavy industry (including basic metals and engineering) had major contribution 80percent of the total employment generated by all industries. In 1991, 2001 and 2019the same group claimed 74 percent, 71.04 and 83.36 percent of the total employment respectively. Thus it is very clearly revealed that in terms of employment there has not been any most important shift in the industrial economy of the study region from 1951-2019.

Table 2. Decadal variation in employment and Industry

\begin{tabular}{lllll}
\hline Years & $\begin{array}{l}\text { No. of industrial } \\
\text { units }\end{array}$ & $\begin{array}{l}\text { Decadal variation } \\
\text { (\%) }\end{array}$ & $\begin{array}{l}\text { No. of } \\
\text { Employments }\end{array}$ & Decadal variation (\%) \\
\hline 1951 & 46 & - & 37629 & - \\
1961 & 104 & 126 & 55079 & 46.37 \\
1971 & 143 & 38 & 82038 & 48.94 \\
1981 & 198 & 38 & 118017 & 43.85 \\
1991 & 216 & 9 & 102039 & -13.51 \\
2001 & 332 & 53 & 109506 & 7.31 \\
2019 & 430 & 98 & 104187 & -5.11 \\
\hline \multicolumn{5}{r}{ Sources: Office of the Chief Inspector of Factories and computed by the authors }
\end{tabular}




\subsection{Spatial Structure of Industries}

An overall spatial structural pattern of manufacturing activities has quite significantly been changed in the Asansol-Durgapur industrial Region during the period from1951-2019. Among the major urban industrial units Durgapur, the most important industrialised centre registered about more or less 34percent of the total number of factory employment in 2019 whereas it had only7percent of the total number of factory employment in 1951. However, during that occasion Durgapur was in its preliminary stage of setting up. In 1951, the majority of factory employment was mainly employed in the area of Burnpur (IISCO works and Kulti the pig iron foundry), Kulti, Raniganj and Andal. Therefore a quaite clear and remarkable picture in terms of spatial structural pattern has been noticed that the western part of the study region was much more industrialised than the rest part of the region during that period. But in 1991 the state of affairs started to change gradually, the glorious position of Kulti, Raniganj, Andal and Burnpur began to declining its significance. As an alternative Durgapur, Chittaranjan and Hindustan Cables have gradually become more industrilised urban units because of abounding major share of the factory workforce. As a consequence, a noticeable swing has been from west to eastward. During the long period of sixty years the pattern of spatial structure of industrialisation has exposed a real fact that is eastward shift characterized by Durgapur capturing significance and weight at the cost of Burnpur, Kulti, Raniganj and Andal. Asansol has registered a slight increase of industrial workforce during this period. The main reason of remarkably uneven distribution of industrial activity in this study region is deep-rooted of its historical evolution and succession of industries in the long past largely because of the prevalence of raw material based industries, in the industrial structure and differences in the regions endowments.

\subsection{Concentration of Industrial Activity}

A significant characteristic of modern industrial scenario is the clustered development or concentration of industries in a region. Such concentration creates the opportunities of economies of scale, encourages competency and indicates betterment at the regional level [29]. Whenever industries are connected with one another; they create an industrial linkage which promotes the growth and development of an industrial complex. Probably the strongest reason for the rising importance in geographical concentrations is that the location in these concentrated regions can offer greater performance to industries. The advantages the industries get are savings in equipment and expenditure on labour and overhead cost and a higher capability for innovation. Moreover, the geographically concentrated regions gained by many ways such as a economies of scale, large flow of knowledge, intense specialization of labour and the connection of a large and outstanding network of subsidiary(auxiliary) industries and expert machinery or a combination of these factors. That's why once a geographical concentration is established, again creates a center of attention for set up of new industries in the region. Therefore, all these advantages justify it.

In order to find out the level of industrialization, the concentration of basic metal \& refractory industry has been taken under consideration. The concentration index for 2001 and 2019 exposed diverse pictures (See Tables 4 and 5). In 2001 there was low concentration of basic metal industry in Asansol is lower as compared to Raniganj, Salanpur, Kanksa and Durgapur recorded very high concentration. Whereas, in 2019 Salanpur and Durgapur lost the record of previous decade, Kanksa kept continuing the identical record and the high concentration prevailed in Jamuria.and Faridpur also (See Fig. 4).

In case of refractory low concentration exists in Durgapur, Kanksa, Andal, Raniganj and high concentration prevails in Salanpur, Kulti, Asansol, Pandabeswar in 2001 (See Fig. 5). In 2019, Kulti, Pandabeswar and Barabani recorded high concentration of refractory industries. On a contrary, Faridpur, Kanksa and Durgapur recorded low and Asansol, Salanpur, Raniganj Andal and Jamuria recorded medium concentration (See Fig. 5). Overall condition shows an increasing trend of the said industry particularly in Salanpur, Kulti, Asansol, Barabani, Raniganj, Pandabeswar and Andal perhaps due to diversification nature of industrial structure.

By \& large engineering industry shows a declining trend in the study region. Among the new-fangled industries registered after 1991 major of them are refractory and ceramics. In order to compute the degree to which exact industries are concentrated in specific region the Location Quotient of industrial workers has been calculated for the study region for two years 1991 and 2011 (See Table 6). 
Table 3. Concentration index of industries-2001

\begin{tabular}{|c|c|c|c|c|c|c|c|c|c|c|c|c|c|}
\hline \multirow{2}{*}{$\begin{array}{l}\text { Block } \\
\text { Municipality }\end{array}$} & \multicolumn{10}{|c|}{ Type of Industry } & \multicolumn{3}{|c|}{ Concentration Index } \\
\hline & $\begin{array}{l}\text { Basic } \\
\text { Metals }\end{array}$ & Engineering & Chemical & Refractory & Wood & Food & Power & Textiles & Others & Total & $\begin{array}{l}\text { Basic } \\
\text { Metal }\end{array}$ & Engineering & Refractory \\
\hline Salanpur & 2 & 4 & 1 & 9 & - & 1 & 1 & - & 9 & 27 & 0.79 & 0.69 & 1.8 \\
\hline Kulti & - & 3 & 2 & 15 & - & - & 2 & - & 4 & 26 & - & 0.54 & 3.2 \\
\hline Asansol & 2 & 12 & 10 & 12 & 2 & 7 & - & - & 19 & 64 & 0.33 & 0.88 & 1.05 \\
\hline Pandabeswar & - & - & - & 2 & 1 & - & - & - & 1 & 4 & - & - & 2.7 \\
\hline Jamuria & & - & 2 & - & - & 3 & 1 & - & 1 & 7 & - & - & - \\
\hline Raniganj & 2 & 7 & 3 & 4 & 2 & 13 & - & - & 2 & 35 & 0.6 & 0.93 & 0.6 \\
\hline Andal & - & 3 & - & 1 & - & - & 1 & - & 2 & 7 & - & 2 & 0.5 \\
\hline Faridpur & - & 7 & 2 & - & - & - & - & - & 1 & 10 & - & 3.26 & - \\
\hline Barabani & - & - & 1 & 3 & - & 1 & - & - & 1 & 6 & - & - & 2.7 \\
\hline Durgapur & 19 & 27 & 13 & 12 & - & 7 & 6 & 2 & 30 & 117 & 1.73 & 1.08 & 0.57 \\
\hline Kanksa & 6 & 8 & 1 & 2 & 2 & 5 & - & - & 5 & 29 & 2.21 & 1.34 & 0.37 \\
\hline Total & 31 & 71 & 35 & 60 & 7 & 37 & 11 & 2 & 75 & 332 & & & \\
\hline
\end{tabular}

Source: Office of the Chief Inspector of Factories \& computed by authors

Concentration Index $(\mathrm{Cl})$ has been calculated by following equation-

$C I=\frac{\frac{e i}{e}}{\frac{E}{E}}$ Where, $e_{i}=$ Number of particular group of industry in a block

$e=$ Number of particular group of industry in the study region

$E_{i}=$ Total number of industries in a block, and $E=$ Total number of industries in the study area. 
Maji and Malik; AJGR, 4(3): 1-17, 2021; Article no.AJGR.69471

Table 4. Concentration Index of Industries-2019

\begin{tabular}{|c|c|c|c|c|c|c|c|c|c|c|c|c|c|}
\hline \multirow{2}{*}{$\begin{array}{l}\text { Blocks I } \\
\text { Municipality }\end{array}$} & \multicolumn{10}{|c|}{ Type of Industry } & \multicolumn{3}{|c|}{ Concentration Index } \\
\hline & $\begin{array}{l}\text { Basic } \\
\text { metal }\end{array}$ & Engineering & Chemical & Refractory & Wood & Food & Power & Textile & Others & Total & $\begin{array}{l}\text { Basic } \\
\text { metal }\end{array}$ & Engineering & Refractory \\
\hline Asansol & 3 & 10 & 4 & 15 & 3 & 12 & - & - & 10 & 57 & 0.19 & 1.14 & 1.23 \\
\hline Durgapur & 39 & 31 & 10 & 11 & - & 3 & 5 & - & 16 & 115 & 1.21 & 1.75 & 0.44 \\
\hline Salanpur & 14 & 5 & 2 & 16 & - & 3 & 1 & - & 11 & 52 & 0.95 & 0.63 & 1.43 \\
\hline Kulti & - & 5 & 1 & 15 & - & 2 & 2 & - & 11 & 36 & - & 0.91 & 1.96 \\
\hline Raniganj & 17 & 3 & - & 12 & 2 & 6 & & - & 4 & 44 & 1.37 & 0.44 & 1.28 \\
\hline Jamuria & 20 & 4 & 2 & 8 & - & 8 & 1 & 1 & 7 & 51 & 1.39 & 0.51 & 0.74 \\
\hline Andal & - & - & - & 2 & - & - & 1 & - & - & 3 & - & - & 3.62 \\
\hline Pandabeswar & - & - & 1 & 1 & - & - & - & - & - & 2 & - & - & 2.71 \\
\hline Faridpur & 2 & 2 & 3 & - & - & - & - & - & 1 & 8 & 0.89 & 1.68 & - \\
\hline Kanksa & 26 & 5 & 1 & 7 & 1 & 3 & 1 & - & 5 & 49 & 1.88 & 0.66 & 0.67 \\
\hline Barabani & - & 1 & - & 5 & - & 1 & 1 & - & 4 & 12 & - & 0.54 & 1.94 \\
\hline Total & 121 & 67 & 24 & 92 & 6 & 38 & 12 & 1 & 69 & 430 & & & \\
\hline
\end{tabular}

Source: Office of the Chief Inspector of Factories \& computed by authors 


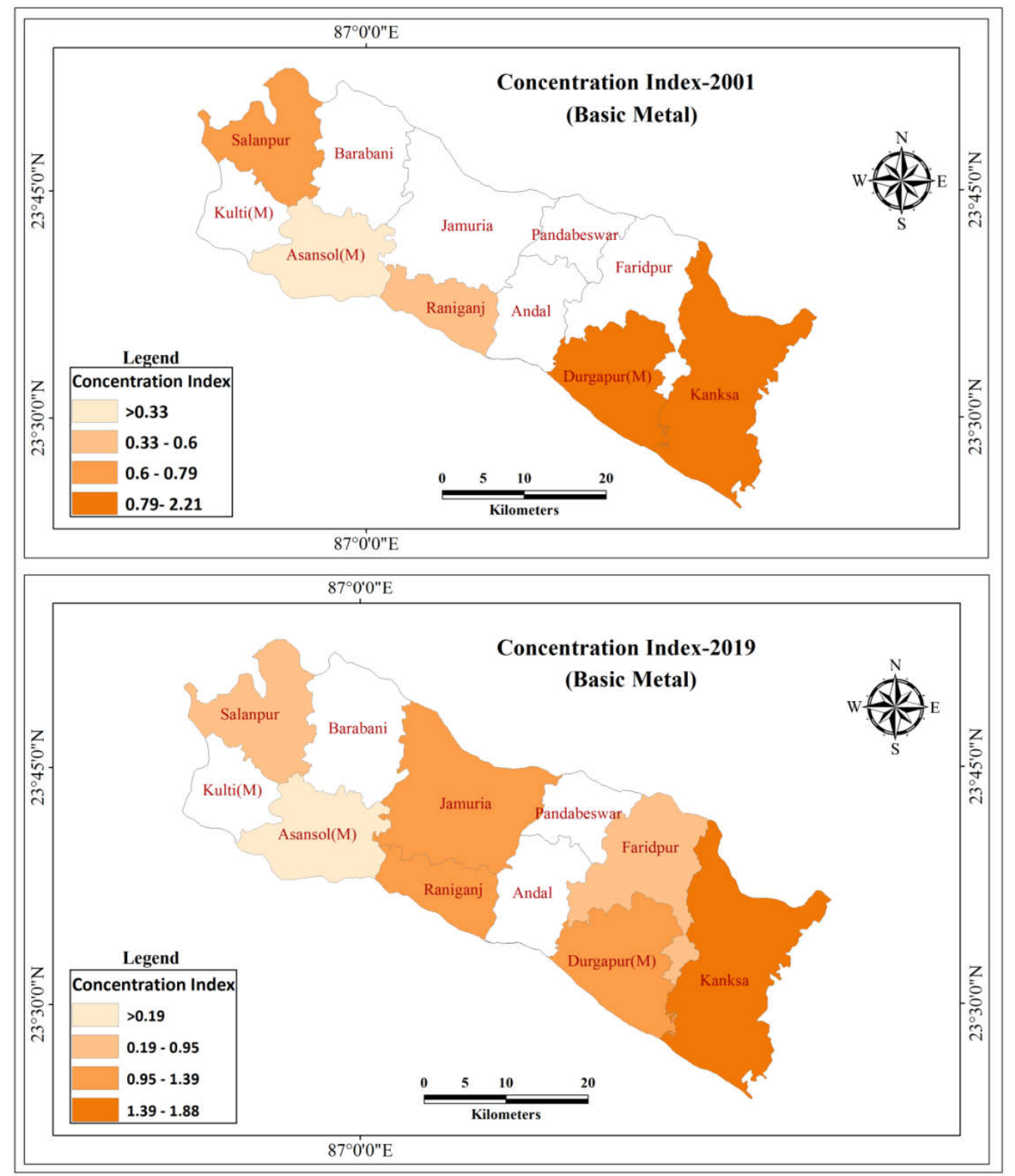

Fig. 4. Map showing the Concentration Index of Basic Metal (2001 \& 2019) Sources: Prepared by authors on the basis of data given in Table-3\&4

It is observed that in 1991 that the $L Q$ value exceeds 1 in case of Salanpur, Asansol and Durgapur whereas the location quotient of in case of Raniganj is very close to1. The state of affairs in 2019 was more or less the similar whenever location quotient exceeded 1 for the areas mentioned above exclusive of Asansol but it was near close to 1 along with Kanksa Block.

Therefore we may come to the conclusion that the industrial population (registered sector only) has been supposed to be concentrated in three urban units only, while Salanpur Block has the Locomotive Works, engaging a massive percentage of industrial workforce, Asansol has the Indian Iron.and Steel Company and Durgapur has the Durgapur Steel Plant, Alloy Steel Plant, Durgapur Projects Limited, Durgapur chemicals and a host of other industrial set up. As per the Census Record there is a lesser degree of concentration of workforce in the manufacturing sector in area of Pandabeswar, 
Faridpur and Barabani block. Because, there are no industrial set up. Consequently the Location
Quotient is a very insignificant percent in these regions.

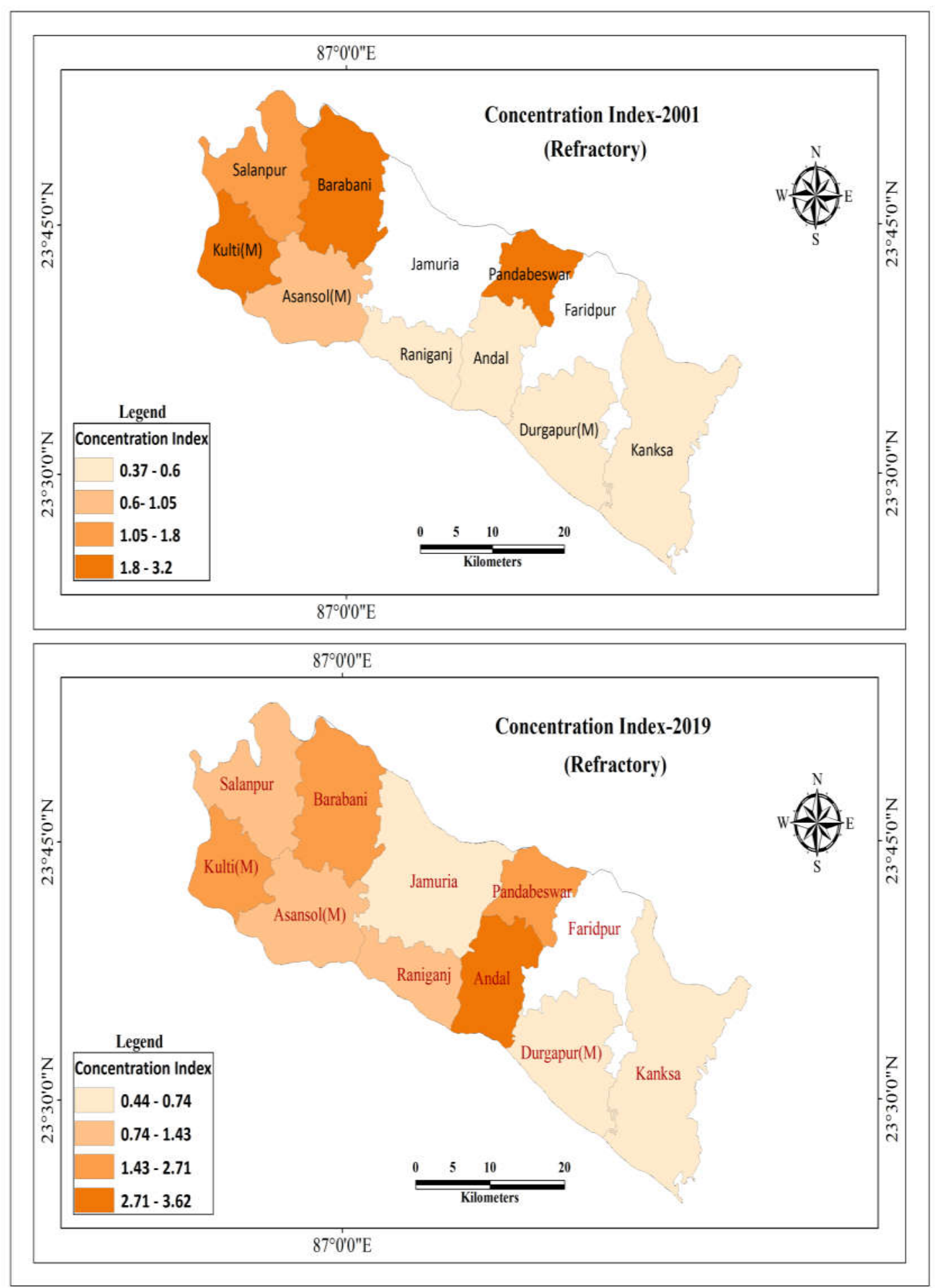

Fig. 5. Map showing the Concentration Index of Refractory (2001 \& 2019) Sources: Prepared by authors on the basis of data given in Table-3\&4 
Table 5. Location Quotient (LQ) for industrial workers

\begin{tabular}{lllll}
\hline Block/Municipality & \multicolumn{2}{c}{$\%$ of Industrial Population to Total Population } & \multicolumn{2}{c}{$\begin{array}{c}\text { Location } \\
\text { Quotient }\end{array}$} \\
\cline { 2 - 5 } & $\mathbf{1 9 9 1}$ & $\mathbf{2 0 1 1}$ & $\mathbf{1 9 9 1}$ & $\mathbf{2 0 1 1}$ \\
\hline Salanpur & 4.81 & 5.01 & 1.04 & 1.27 \\
Kulti(M) & 2.92 & 2.03 & 0.63 & 0.51 \\
Asansol(M) & 5.09 & 3.52. & 1.12 & 0.88 \\
Pandabeswar & 0.09 & 0.11 & 0.01 & 0.02 \\
Kanksa & 1.03 & 3.48 & 0.22 & 0.87 \\
Jamuria & 0.28 & 0.91 & 0.06 & 0.22 \\
Raniganj & 2.36 & 2.87 & 0.51 & 0.71 \\
Andal & 1.19 & 1.64 & 0.26 & 0.41 \\
Faridpur & 0.36 & 0.69 & 0.07 & 0.17 \\
Barabani & 0.05 & 0.48 & 0.01 & 0.12 \\
Durgapur(M) & 13.88 & 9.82 & 3.02 & 2.46 \\
\hline
\end{tabular}

Sources: Calculated by the authors
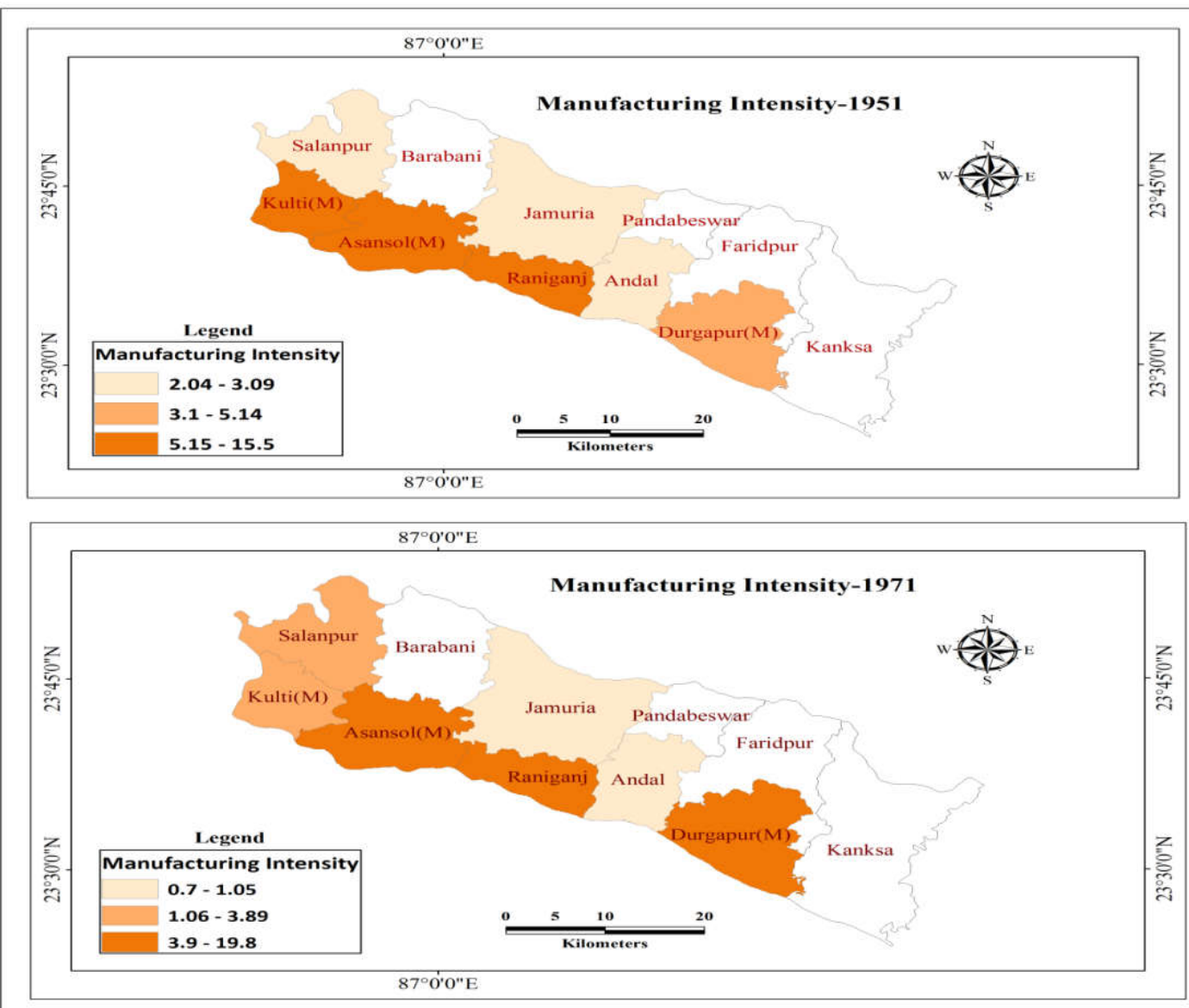

Fig. 6. Map showing the manufacturing intensity of industries (1951-1971) Sources: Prepared by the authors on the basis of data given in Table-6 
Table 6. Manufacturing intensity of industries (1951-2019)

\begin{tabular}{|c|c|c|c|c|c|c|c|c|c|c|c|c|c|c|c|}
\hline \multirow[t]{2}{*}{ Block / Municipality } & \multicolumn{6}{|c|}{ No. of manufacturing units. } & \multicolumn{4}{|c|}{ No. of employment } & \multicolumn{5}{|c|}{ Manufacturing intensity } \\
\hline & 1951 & 1971 & 1991 & 2001 & 2019 & 1951 & 1971 & 1991 & 2001 & 2019 & 1951 & 1971 & 1991 & 2001 & 2019 \\
\hline Kanksa & - & - & 21 & 29 & 49 & - & - & 1330 & 1703 & 17753 & - & - & 4.91 & 4.45 & 5.81 \\
\hline Salanpur & 2 & 9 & 8 & 27 & 53 & 334 & 7676 & 6859 & 7768 & 15052 & 2.04 & 3.19 & 1.9 & 4.17 & 6.23 \\
\hline Kulti & 12 & 11 & 20 & 26 & 36 & 10510 & 7590 & 6096 & 6227 & 805 & 12.37 & 3.89 & 4.7 & 4.01 & 4.19 \\
\hline Asansol & 15 & 29 & 39 & 64 & 57 & 16498 & 23879 & 20350 & 21130 & 13512 & 15.52 & 10.28 & 9.21 & 9.79 & 6.71 \\
\hline Pandabeswar & - & - & 2 & 4 & 2 & - & - & 120 & 164 & 34 & - & - & 0.47 & 0.61 & 0.23 \\
\hline Jamuria & 2 & 3 & 3 & 7 & 51 & 697 & 132 & 559 & 658 & 8124 & 2.05 & 1.05 & 0.7 & 1.07 & 5.95 \\
\hline Raniganj & 10 & 33 & 26 & 35 & 44 & 4405 & 6995 & 5439 & 5622 & 12287 & 10.26 & 11.58 & 6.09 & 5.39 & 5.69 \\
\hline Andal & 3 & 2 & 5 & 5 & 3 & 2385 & 509 & 1809 & 1809 & 585 & 3.09 & 0.7 & 1.17 & 1.17 & 0.35 \\
\hline Faridpur & - & - & 10 & 10 & 8 & - & - & 330 & 330 & 655 & - & - & 2.33 & 2.33 & 0.93 \\
\hline Barabani & - & - & 2 & 6 & 12 & - & - & 59 & 175 & 379 & - & - & 0.46 & 0.61 & 1.39 \\
\hline Durgapur & 5 & 56 & 78 & 117 & 115 & 2800 & 35257 & 59123 & 63920 & 35001 & 5.14 & 19.79 & 18.51 & 18.08 & 13.58 \\
\hline Total & 49 & 143 & 214 & 330 & 430 & 37629 & 82038 & 102074 & 109506 & 104187 & & & & & \\
\hline
\end{tabular}

Sources: Chief Inspector of Industries of Paschim Bardhaman \& computed by the authors

Manufacturing intensity (M.I.) has been calculated by the following equation:

$$
\text { M.I. }=\frac{X+Y}{2}
$$

Where, $X=$ Number of total industries in the Block/Number of total industries in the Study Region $\times 100$.

$Y=$ Number of person employed in the Block/Number of person employed in the Study Region. 


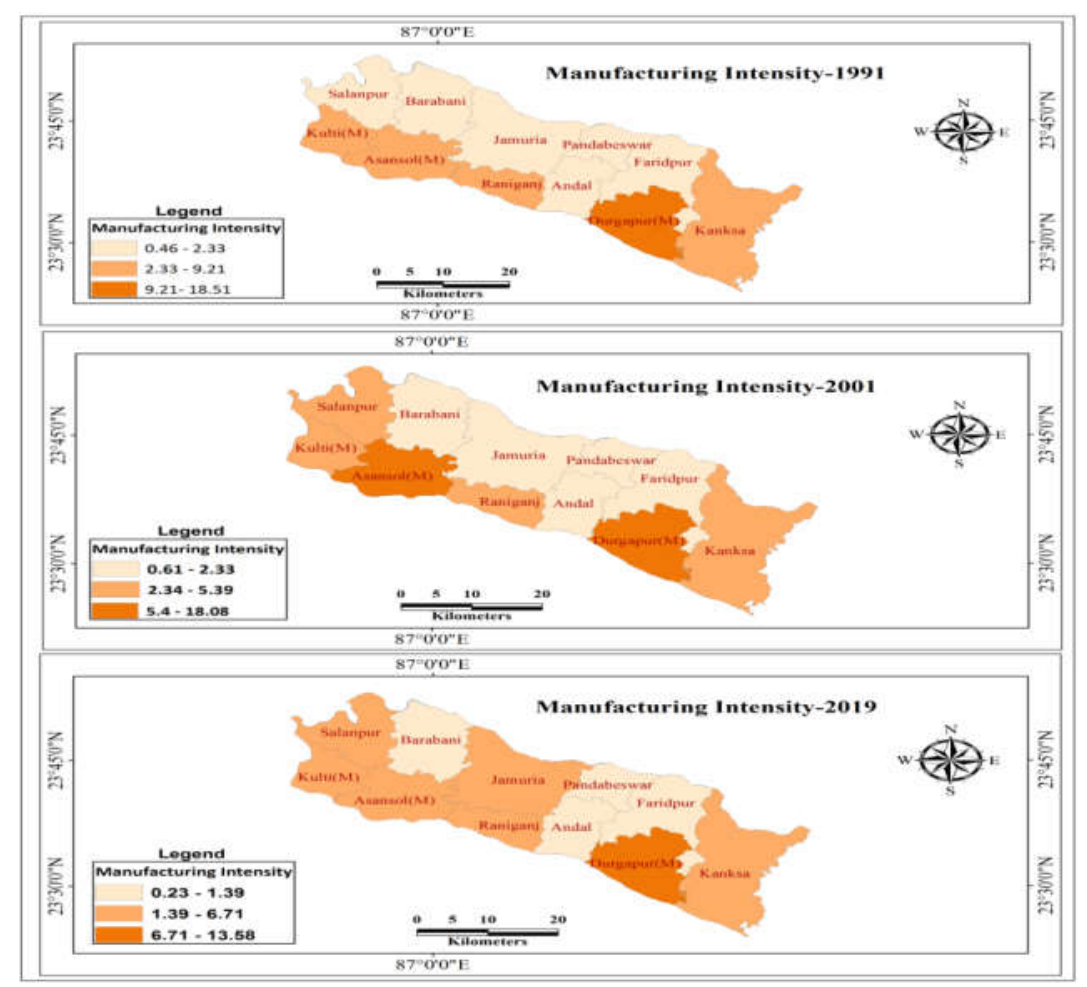

Fig. 7. Map showing the Manufacturing Intensity of Industries (1991-2019) Sources: Prepared by the authors on the basis of data given in Table-6

\subsection{Concentration of Industrial Workforce}

For evaluation the level of industrialisation in this region manufacturing intensity has also been computed. The number of industrial units and employment has been taken into consideration as a parameter for each Block, Municipality and Municipal Corporation of Asansol-Durgapur Region for the period of 1951-2019 (See Table 6).

In 1951, manufacturing intensity was found low in Salanpur and Jamuria, it was the medium is Andal, high in Durgapur and very high in Asansol Kulti and Raniganj (See Fig. 6). The position did not change much until 1971 excluding Salanpur and Durgapur area where the level of industrialization depicted a noticeable enhancement whereas in case of Asansol there was a sharp declining trend. Andal too experienced a striking decline (See Table 6). In 1991, manufacturing intensity was high in areas of Kulti, Raniganj,Asansol, and Kanksa whereas Faridpur and Salanpur recorded medium intensity whereas in case of Barabani, Jamuria, Pandabeswar very Low manufacturing intensity persisted there but very high in Durgapur (See
Fig. 6). In 2001Asansol and Durgapur had very high manufacturing intensity, whereas the Kulti, Salanpur, Raniganj and Kanksa blocks registered high manufacturing intensity and the regions with low intensity are Baeabani, Jamuria, Andal and Pandabeswar (See Fig. 6). The situation was similar in 2019 exclusive of Jamuria experienced high manufacturing intensity than the previous decade (See Fig. 6).

The Fig. 7 also indicates a good indication of coming out of Durgapur as an important manufacturing industrial complex due to the closure of Kulti plant, Hindustan Cables \& Burn Standard. Besides, the spatial trend reveals a quite clear picture of emergence of the eastern part as a most important industrial zone and a slow but sure turn down of industries in the western part of Asansol- Durgapur region.

\section{MAJOR OUTCOMES AND CONCLUSION}

Few major findings are highlighted below-

1. Durgapur emerged as a prominent industrial complex resulting into seismic 
shift in industrial concentraion from West to East. In Asansol-Durgapur Industrial Region manufacturing activity is highly localised. Andal in spite of being situated very close proximity to Durgapur industrial complex has unfortunately witnessed an industrial decline. Concentration of engineering industry has decreased a great deal in the study area.

2. Throughout the study period of fifties, sixties and seventies mining and manufacturing fully dominated the region's economic activity. However, in the decade of eighties the region experienced declining trend because of an aftermath of the widespread industrial sickness of all over the state.

3. Uneven industrialization throughout the entire region of the study area is a significant characteristic. The concentration of engineering industries declined significantly particularly in and around Kulti and Asansol. Refractories revealed a positive trend even in the adverse situation of industries. Manufacturing intensity indicated a positive trend in case of Durgapur.

4. The study's results give us an idea that the manufacturing sector's employment contribution to regional economy has not been increased considerably since 1971 because of shifting and concentration of manufacturing activities to comparatively in particular regions.

5. It is noteworthy that the opportunity of industrialization failed to reach to the entire region and the peripheral areas of Durgapur has remained industrially backward yet. Though there is no reasonable justification of industrial agglomeration.

In conclusion it can be said that the deserved growth rate of manufacturing industries has not been attained. It is, therefore, clear that Industrial Policy of Government completely failed to fulfill the gap between target and achievement, and consequently a few regions like Barabani, Pandabeswar, Faridpur and Andal have still remained in the low manufacturing intensity. Therefore, the focal point of industrial policy of Government should be to make way out of unbalanced industrialisation and untimely deindustrialisation to attain the regional as well as national economic development through the path of industrialization.

\section{DISCLAIMER}

The products used for this research are commonly and predominantly use products in our area of research and country. There is absolutely no conflict of interest between the authors and producers of the products because we do not intend to use these products as an avenue for any litigation but for the advancement of knowledge. Also, the research was not funded by the producing company rather it was funded by personal efforts of the authors.

\section{COMPETING INTERESTS}

Authors have declared that no competing interests exist.

\section{REFERENCES}

1. Bharati RK. Industrial estates in developing economics; National Publishing House, New Delhi; 1978.

2. Balssa B. The process of industrial development and alternative development strategies. USA by Princeton University Press at Princeton. New Jersey. 1980: 141:1.

3. Romer P. 'Endogenous Technological Change', Journal of Political Economy. 1990;98(5):71-102.

4. Lucas RE. 'On the Mechanics of Economic Development'. Journal of Monetary Economics. 1988;22 (1):3-42.

5. Akyuz Y. 'Industrial tariffs, international trade, and development', In: Cimoli M., Dosi G, Stiglitz J. (Eds.). Industrial policy and development the political economy of capabilities accumulation. Oxford University Press, New York. 2009;144-174.

6. Lall S. Competitiveness, technology and skills, edward elgar, Cheltenham; 2001.

7. Rodrik D, Subramanian A. 'From "Hindu Growth" to productivity surge: The mystery of the indian growth transition'; 2004.

8. Syrquin M. Patterns of structural change' in H. Chenery, T.N. Srinivasan (eds), Handbook of development economics, North Holland, Amsterdam. 1988;1:205248.

9. Szirmai A. 'Industrialisation as an engine of growth in developing countries', Working paper 2009-010, UNU -MERIT; 2009.

10. Szirmai A. Industrialisation as an engine of growth in developing countries, 19502005; 2012. 
11. Lavopa A. Structural transformation and economic development. Can development traps be avoided? PhD dissertation, Maastricht university and United Nations university. Structural Change and Economic Dynamics. 2015; 23:406-420.

12. Kuznets S. Quantitative aspects of the economic growth of nations: II. Industrial distribution of national product and labor force. Economic Development and Cultural Change. 1957;5:1-111.

13. Chenery H. Structural change and development policy. Oxford, UK: Oxford University Press; 1979.

14. Acharya A. Singapore's foreign policy: the search for regional order. Speech by minister mentor lee kuan yew at the 37th Jawaharlal Nehru Memorial Lecture, New Delhi, 21 November 2005, "India in an Asian Renaissance", 178-192. World Scientific Publishing Company; 2007.

15. Amirapu A, Subramanian A. Manufacturing or services? An Indian illustration of a development dilemma. Center for global development working paper 409. Washington, DC: Center for Global Development; 2015.

16. Barro RJ. Human capital and growth. American Economic Review. 2001;91:1217.

17. Kaldor N. Strategic factors in economic development. ithaca: New York state school of industrial and labor relations, Cornell University. 1967;48.

18. Dasgupta S, Singh A. "Manufacturing, services and premature deindustrialization in developing countries." United Nations University World Institute of Development Economic Research. Paper No. 2006/49; 2006.

19. Rodrik D. "Premature Deindustrialization." NBER Working Paper Series 20935; 2015.
20. Ghani E, O'Connell SD. "Can service be a growth escalator in low income countries?" World Bank Group Policy Research Working Paper No. 697; 2014.

21. Kathuria VR, Natarajan R. "Is manufacturing an engine of growth in India in the post-nineties?" Journal of South Asian Development. 2013;8(3):385-408.

22. Zhu S, Wang C. Shifts in China's economic geography studies in an era of industrial restructuring. Prog. Geogr. 2018;37:865879.

23. Li C, Wu K, Gao X. Manufacturing industry agglomeration and spatial clustering: Evidence from Hebei Province, China. Environ. Dev. Sustain. 2020;22:29412965.

24. Li L, Ma Y. Spatial-temporal pattern evolution of manufacturing geographical agglomeration and influencing factors of old industrial base: A case of Jilin Province, China. Chin. Geogr. Sci. 2015;25:486-497.

25. Mori T, Smith TE. On the spatial scale of industrial agglomerations. J. Urban Econ. 2015;89:1-20.

26. Larsson JP, Andersson M, Klaesson J. How local are spatial density externalities? Neighbourhood Effects in Agglomeration Economies Reg. Stud. 2016;50:10821095.

27. Zhao Q, Li Z, Zhao Z, Ma J. Industrial policy and innovation capability of strategic emerging industries: Empirical evidence from Chinese new energy vehicle industry. Sustainability. 2019;11:2785.

28. Rodrik D. "Unconditional convergence in manufacturing." The Quarterly Journal of Economics. 2013;128(1):165-20.

29. Rana Pratap. Growth and regional pattern of industrial complexes: A case study of Bihar; Concept Publishing, New Delhi; 1985.

(c) 2021 Maji and Malik; This is an Open Access article distributed under the terms of the Creative Commons Attribution License (http://creativecommons.org/licenses/by/4.0), which permits unrestricted use, distribution, and reproduction in any medium, provided the original work is properly cited.

Peer-review history:

The peer review history for this paper can be accessed here: http://www.sdiarticle4.com/review-history/69471 